

\title{
Estudo anatômico do forame palatino maior por meio de imagens de tomografia computadorizada de feixe cônico
}

\section{Karen C. Formigoni*, Ana C. R. Brito, Polyane M. Queiroz, Deborah Q Freitas}

\section{Resumo}

O objetivo do presente estudo foi determinar a posição e formato do forame palatino maior (FPM), o comprimento médio do canal palatino maior (CPM) e o ângulo formado entre o palato duro e a entrada do CPM, por meio de tomografia computadorizada de feixe cônico (TCFC). Foram avaliados exames tomográficos de 112 pacientes. Observou-se que o FPM está mais próximo do 3 molar (59,39\%), independente de sexo ou lado. A largura média do FPM foi de 2,11 mm (axial) e de 2,44 mm (coronal). As maiores distância em relação ao FPM foram para homens. A maioria $(75,90 \%)$ dos canais apresentam dois segmentos. O ângulo entre a entrada do CPM e plano paralelo ao palato duro foi de $67,78^{\circ}$. As distâncias entre o FPM e os pontos anatômicos estudados foram maiores no sexo masculino. Conclui-se que, na maioria dos casos, a FMP encontra-se mais proximo ao 3o molar e para bloqueio do no $\mathrm{n}$. maxilar a agulha deve ser inserida a $67^{\circ}$, em relação ao plano oclusal.

Palavras-chave: maxila, tomografia computadorizada de feixe cônico, bloqueio nervoso.

\section{Introdução}

O bloqueio FPM é muito utilizado na Odontologia, principalmente em procedimentos que envolvem a manipulação de tecidos da região do palato. As injeções no palato são procedimentos traumáticos para muitos pacientes, por isso o profissional deve empregar técnicas menos traumáticas. Foram avaliadas TCFC de 112 pacientes, nas reconstruções axial, coronal e sagital. Foram determinadas: a largura do FPM, sua posição em relação aos molares superiores, a distância desse forame à sutura palatina mediana (SPM), à espinha nasal posterior (ENP) e ao forame incisivo (FI). Foi calculada a extensão do CPM e seu padrão de percurso entre a fossa pterigomaxilar e FPM; e ainda o ângulo formado entre o plano paralelo ao palato duro e a entrada do CPM.

\section{Resultados e Discussão}

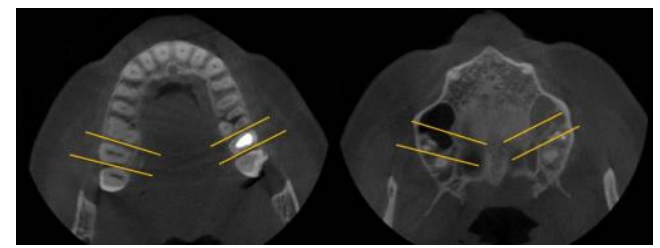

Figura 1. Reconstrução axial mostrando a posição do FPM em relação aos molares superiores.

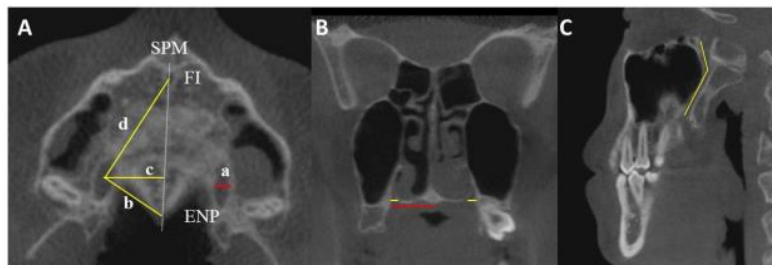

Figura 2. Reconstruções axial (A), coronal (B) e sagital (C) onde são observadas as medidas realizadas para se obter a largura e posição do FPM, bem como o padrão do CPM.
Tabela 1. Distâncias entre o FPM e os pontos anatômicos de referência estudados, nos planos axial e coronal

\begin{tabular}{|c|c|c|c|c|c|}
\hline \multirow{20}{*}{$\begin{array}{l}A \\
X \\
I \\
A \\
L\end{array}$} & & & & Medida & $p$ \\
\hline & \multirow{4}{*}{$\begin{array}{l}\text { Largura } \\
\text { FPM }\end{array}$} & \multicolumn{2}{|r|}{ Geral } & $2.11(0.39)$ & \\
\hline & & \multirow[t]{2}{*}{ Sexo } & Masculino & $2.30(0.17)$ & \multirow[t]{2}{*}{$<0,0001^{*}$} \\
\hline & & & Feminino & $1.99(0.11)$ & \\
\hline & & Lado & $\begin{array}{c}\text { Direito } \\
\text { Esquerdo }\end{array}$ & $\begin{array}{l}2.12(0.16) \\
2.09(0.15)\end{array}$ & 0,547 \\
\hline & \multirow{5}{*}{$\begin{array}{l}\text { FPM- } \\
\text { ENP }\end{array}$} & \multirow{3}{*}{ Sexo } & Geral & $16.03(1.36)$ & \\
\hline & & & Masculino & $16.61(1.94)$ & \multirow[t]{2}{*}{$<0,0001^{*}$} \\
\hline & & & Feminino & $15.68(1.49)$ & \\
\hline & & \multirow[t]{2}{*}{ Lado } & Direito & $16.00(1.52)$ & \multirow[t]{2}{*}{0,747} \\
\hline & & & Esquerdo & $16.06(2.20)$ & \\
\hline & \multirow{5}{*}{$\begin{array}{l}\text { FPM- } \\
\text { SPM }\end{array}$} & \multirow{3}{*}{ Sexo } & Geral & $14.94(1.32)$ & \\
\hline & & & Masculino & $15.46(1.87)$ & \multirow{2}{*}{$<0,0001^{*}$} \\
\hline & & & Feminino & $14.63(1.43)$ & \\
\hline & & \multirow[t]{2}{*}{ Lado } & Direito & $15.04(1.69)$ & \multirow[t]{2}{*}{0,267} \\
\hline & & & Esquerdo & $14.84(1.81)$ & \\
\hline & \multirow[t]{5}{*}{ FPM-FI } & & Geral & $36,75(3,15)$ & \\
\hline & & \multirow[t]{2}{*}{ Sexo } & Masculino & $37.68(8.4)$ & \multirow[t]{2}{*}{$0,0006^{*}$} \\
\hline & & & Feminino & $26.19(10.07)$ & \\
\hline & & \multirow[t]{2}{*}{ Lado } & Direito & $36.80(7.80)$ & \multirow[t]{2}{*}{0,404} \\
\hline & & & Esquerdo & $36.70(12.14)$ & \\
\hline \multirow{10}{*}{$\begin{array}{l}\text { C } \\
\text { O } \\
\text { R } \\
\text { O } \\
\mathrm{N} \\
\mathrm{A} \\
\mathrm{L}\end{array}$} & \multirow{5}{*}{$\begin{array}{l}\text { Largura } \\
\text { FPM }\end{array}$} & \multirow{3}{*}{ Sexo } & Geral & $2.44(1.56)$ & \\
\hline & & & Masculino & $2.52(0.21)$ & \multirow[t]{2}{*}{$<0.0001^{*}$} \\
\hline & & & Feminino & $2.09(0.14)$ & \\
\hline & & \multirow[t]{2}{*}{ Lado } & Direito & $2.26(0.20)$ & \multirow[t]{2}{*}{0,073} \\
\hline & & & Esquerdo & $2.24(0.22)$ & \\
\hline & \multirow{5}{*}{$\begin{array}{l}\text { FPM- } \\
\text { SPM }\end{array}$} & \multirow{3}{*}{ Sexo } & Geral & $14.82(1.98)$ & \\
\hline & & & Masculino & $15.34(2.05)$ & \multirow[t]{2}{*}{$0,002^{*}$} \\
\hline & & & Feminino & $14.65(2.78)$ & \\
\hline & & Lado & Direito & $14.95(3.21)$ & 0,355 \\
\hline & & & Esquerdo & $14.86(2.03)$ & \\
\hline
\end{tabular}

\section{Conclusões}

O FPM está mais próximo ao $3^{\circ}$ molar e sua distância aos pontos anatômicos foi maior no sexo masculino; a maioria dos canais apresentam dois segmentos; o ângulo de inserção da agulha deve ser de $67^{\circ}$.

\section{Agradecimentos}

À CNPq pela bolsa concedida.

${ }^{1}$ Malamed SF. Manual de anestesia local. 6 ed. Rio de Janeiro: Elsevier, 2013. ${ }^{2}$ Ykuda CRS, Cardoso CL, Ferreira-Júnio O, Lauris JRP, Souza PHC, Rubira-Bullen, IRF. Position of the greater palatine foramen: an anatomical study through cone beam tomography images. Surg Radiol Anat. 2013. 35: 837-842. 